\title{
Impact of Service Quality in the Nail Esthetic Industry on Customer Satisfaction, Trust, and Revisit Intention
}

\author{
Sun-Ju Park \\ Department of Beauty Health Care, Yongin University, Yongin-si, Gyeonggi-do, Korea
}

\author{
Corresponding author: Sun-Ju Park, \\ Department of Beauty Health Care, Yongin \\ University, 134 Yongindaehak-ro, Cheoin-gu, \\ Yongin-si, Gyeonggi-do 17092, Korea \\ Tel.: +82 3180203694 \\ Fax: +82 3180203694 \\ Email: sj7864@hanmail.net
}

Received November 26, 2016

Revised April 29, 2017

Accepted May 8, 2017

Published September 30, 2017

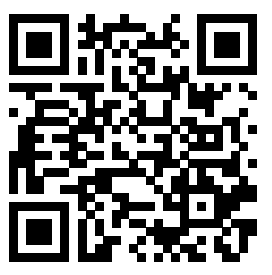

\begin{abstract}
Purpose: This study aims to identify the effects of service quality on customer revisit intention in the nail esthetic industry in terms of customer satisfaction and trust. Methods: This research was to identify how customers' reaction to the service quality affects customer satisfaction, trust, and revisit intention in the nail esthetic industry. For this purpose, Statistical Package for the Social Sciences (SPSS) was used for statistical analysis. Results: From a marketing perspective, the results demonstrated that the most influential factors for service quality in the nail esthetic industry are economy, conviction, sympathy, and kindness. Conclusion: In the nail esthetic industry, economy, conviction, sympathy, and kindness as recognized by the customer were the main factors influencing future customer satisfaction, trust, and revisit intention. Based on these factors, the nail esthetic industry should endeavor to meet customer needs and be more customer-oriented and trustworthy. Building a long-term relationship with customers will enable the nail esthetic industry ensure a higher level of customer revisit intention.
\end{abstract}

Keywords: Service quality, Customer satisfaction, Trust, Revisit intention, Nail esthetic industry

\section{Introduction}

우리나라 국가경제에서 서비스산업의 비율이 $60 \%$ 를 넘게 나타 날 정도로(2001년 국가 국내총생산 기준) 서비스산업의 중요성은 매 우 커지고 있는 추세이며 향후 서비스산업에 대한 학문적 관심은 지 속적으로 증가할 것으로 예상된다. 특히 서비스 마케팅 측면에서 볼 때 성공적인 기업의 마케팅 전략은 결국 고객과의 질 및 고객서비스 만족에 바탕을 두고 있으며 이런 점에서 볼 때 서비스 마케팅과 이 와 관련된 요인들에 대한 학문적 연구의 필요성은 크다고 할 수 있 다(Oliver, 1997).

네일 미용서비스업은 다른 서비스 분야에 비해 기술 의존도가 매 우 높은 분야이다. 이전의 네일 미용산업은 비교적 공급자가 한정된 환경으로 존재하여 별다른 연구 없이 편안하게 네일 뷰티샵을 경영 할 수 있었던 반면, 지금은 여성의 사회참여 확대로 인해 소비자들 의 수준이 향상되었을 뿐만 아니라 네일 샵 경쟁 과열로 인한 네일 미용산업의 환경적 변화의 시기에 놓여 있다. 그런데 이처럼 급변하 는 미용서비스산업 시장에서 서비스 마케팅에 대한 기존의 고정관
념을 변화시키는 것은 매우 어려운 상황이다. 특히 서비스를 받고자 하는 고객들은 그들이 찾은 점포에서 많은 정보를 획득하기를 원하고 만족감을 얻으려 하기 때문에, 이들의 욕구를 충족시켜 줌으로써 재 방문 의도를 높이기 위한 노력을 기울여야 한다(Cho \& Choi, 2011).

신규고객을 창출하는 것보다 지속적으로 기존 고객을 관리하고 관계를 유지하는 것이 고객들로 하여금 충성도 및 재구매 의도를 높여 이익을 증대시키는데 더욱 효과적이다. 또한, 신규고객을 창 출하기 힘든 최근 산업 분위기 속에서 기존의 경쟁적인 시장 환경 을 이미 형성했다는 것은 기업 입장에서 매우 중요한 경쟁력을 확 보한 것으로 볼 수 있다. 이에 기업에서는 기존 고객과의 관계를 지 속적으로 유지하고 고객의 이탈을 막기 위하여 우호적인 관계를 서 비스 마케팅적 관점에서 유지함으로써 고객의 몰입 및 충성도를 만 들어 낼 수 있는 관계 마케팅이 강조되고 있다(Oliver, 1997). 기존의 Houston (1986)의 연구에서는 고객과 기업 사이에 중요한 접점의 역할을 하는 종업원들이 고객에 대해 보이는 태도와 행위에 따라 고 객만족, 고객충성도, 업체의 성과, 서비스의 전환 등이 변화되었다 고 보고하였다. 이는 곧 접점 직원의 행동은 기업을 대표하는 행동 


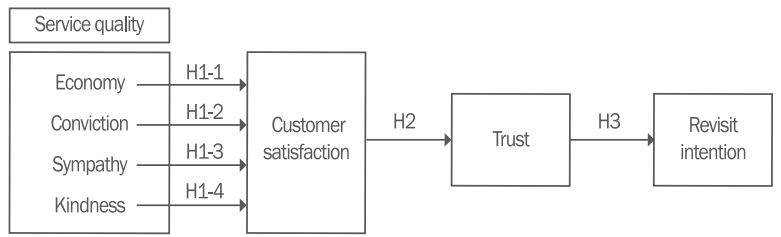

Figure 1. Research model

A model for the effects on the customer royalty of service quality. Customer satisfaction and trust were used as parameters.

으로 볼 수 있으며 고객의 충성도에 바로 효과를 끼칠 수 있는 특성 을 갖고 있기 때문에, 접점 직원의 행동은 기업의 성공에 영향을 미 치는 중요한 요소 중의 하나라고 할 수 있다.

네일 미용산업에 있어서 문화의식의 질적 수준과 경제적 풍요가 높아짐에 따라 고객의 인식이 높아지고 있으며 상대방에게 불편함 을 주지 않고 경쟁사회에서의 자신의 미에 대해 표현할 수 있는 능 력의 중요성이 강조되고 있다. 고객과 직접적으로 대면해 서비스를 제공하기 때문에 네일 서비스의 경우는 작은 요소만으로 고객을 만 족시키는 부분에 어려움이 있다. 또한 개성을 살리고자 하는 개개인 의 소비층이 높아지고 있는 추세라 소비자들에게 맞는 서비스를 제 공하기 위한 인식의 변화가 필요하게 되었다. 이와 더불어 소비자의 재방문 의도를 높이기 위해서는 소비자의 만족이 서비스의 중요한 요인이 된다. 미용기술과 마찬가지로 네일 미용서비스는 하나의 상 품으로서 서비스 질의 고객만족을 위하여 고객에게 계속적으로 제 공하는 모든 활동을 뜻한다.

경쟁이 치열한 네일 미용산업은 최근 몇 년 사이 눈에 띄게 발전 하고 있는 반면에, 관계 마케팅과 관련된 네일 미용산업 연구는 아 직도 미비한 실정이다. 따라서 네일 미용산업의 치열한 경쟁과 급변 하는 환경에 대응하기 위해, 서비스 품질에 대한 마케팅을 차별화하 고 지속적인 고객과의 관계를 유지하면서 고객만족 및 신뢰, 재방문 의도를 제고시킬 수 있는 마케팅 전략의 필요성이 요구되고 있다.

본 연구에서는 네일 미용산업을 이용하는 고객을 대상으로 하여 서비스 품질에 따라 재방문 의도에 어떠한 영향을 미치는지 고객만 족 및 신뢰와 함께 실증분석을 통해 관계를 규명하고자 한다. 이와 더불어 네일 미용산업의 마케팅적 시사점을 제시하고자 한다.

\section{Methods}

\section{1. 연구의 모형}

본 연구에서는 선행연구를 바탕으로 네일 미용산업의 서비스 품 질이 고객만족, 신뢰 및 재방문 의도에 미치는 영향에 대해 알아보 기 위해 본 연구의 모형을 Figure 1과 같이 제시하였다.

\section{2. 변수의 조작적 정의}

본 연구에서는 설정한 모형과 가설을 검증하기 위해 다음과 같은 요인으로 측정하였다.

\section{1) 서비스 품질}

네일 미용산업의 서비스 품질을 측정하기 위해 관련 선행연구 Kim et al. (2002)을 토대로 네일 미용산업의 서비스에 맞게 수정 보 완하여 경제성, 확신성, 공감성, 친절성 네 가지 차원으로 구성되었 다. 경제성은 "네일 서비스 품질 대비 가격 적정성, 네일 기술 대비 가격 적정성" 으로 정의하였으며, 확신성은 “원하는 스타일을 정확 히 시술, 약속시간에 정확히 시술”로 정의하였고, 공감성은 “네일 시 술 절차의 간편성, 예약 신청의 편리성”으로 정의하였고, 친절성은 "접점 종업원의 친절도, 문제 발생시 접점 종업원의 친절도, 예약 직 원의 친절도”로 정의하였으며, 총 9 가지 문항에 대해 5 점 척도로 측 정하였다.

\section{2) 고객만족}

고객만족은 해당 서비스업체를 이용하는 것에 대해 느끼는 전반 적인 믿음을 측정할 수 있는 항목으로 구성하였다. Anderson et al. (1994)의 연구에 근거하여, "네일 미용서비스 관계의 만족감, 네일 미용서비스 수준의 적절함, 관계의 즐거움, 서비스의 유익함"의 4 가 지 문항에 대해 5 점 척도로 측정하였다.

\section{3) 신뢰}

신뢰는 믿고 지속적으로 거래할 수 있는 전반적인 믿음으로 정의 하였다. 신뢰는 Morgan \& Hunt (1994)의 선행연구를 바탕으로, "네 일 미용산업의 서비스는 나의 기대에 어긋나지 않는다, 네일 미용산 업은 고객을 위해 고품질 제품을 사용한다, 네일 미용산업의 서비스 품질은 동일하게 유지되고 있다, 네일 미용산업의 서비스는 믿을만 하다"의 4 가지 문항에 대해 5점 척도로 측정하였다.

4) 재방문 의도

재방문 의도는 "네일 미용산업의 서비스 품질과 관련하여 동일한 네일 미용산업을 향후 계속 이용할 가능성”이라고 정의하였다. 본 연구에서는 Oliver (1980)의 선행연구를 바탕으로 “합리적인 비용을 받는다고 생각하는지, 다른 사람들한테 추천할 의도가 있는지, 다시 방문할 의도가 있는지, 방문 빈도가 높은지”의 4 가지 문항을 구성하 여 리커트 5점 척도로 측정하였다.

\section{3. 가설 설정}

본 연구는 실증분석을 위해 이론적 배경 및 선행연구를 바탕으로 네 일 미용산업의 서비스 품질이 고객만족, 신뢰 및 재방문 의도에 어떠 한 영향을 미치는지 인지하기 위하여 연구모형을 구축하였으며, 이를 근거로 실증연구에서 검증해야 할 가설을 다음과 같이 설정하였다. 
1) 네일 미용산업의 서비스 품질이 고객만족에 미치는 영향 관계

Cronin \& Taylor (1992)는 실증분석을 통하여 서비스 품질은 고 객만족의 선행변수임을 밝혔고, Lee (2010)의 연구도 서비스 품질 이 가치, 만족 및 충성도 간에 유의한 영향 관계가 있음을 검증했다. Rho \& Oh (2008)의 선행연구에서도 서비스 품질은 고객의 신뢰와 만족에 영향을 미친다고 하였는데, 서비스 품질은 다양한 차원으로 구성될 수 있고, 서비스 산업이나 제공되는 서비스 특성에 따라 각 기 상이한 차원으로 도출될 수 있다. 이와 같은 선행연구를 바탕으 로 서비스 품질은 고객만족에 유의적인 영향을 미칠 것이라고 추론 할 수 있으므로 다음과 같은 가설을 설정할 수 있다.

H1: 네일 미용산업의 서비스 품질은 고객만족에 유의적인 영향을 미칠 것이다.

H1-1: 경제성은 고객만족에 유의적인 영향을 미칠 것이다.

$\mathrm{H} 1-2$ : 확신성은 고객만족에 유의적인 영향을 미칠 것이다.

H1-3: 공감성은 고객만족에 유의적인 영향을 미칠 것이다.

$\mathrm{H1}-4$ : 친절성은 고객만족에 유의적인 영향을 미칠 것이다.

2) 네일 미용산업의 고객만족이 신뢰에 미치는 영향 관계

고객만족과 신뢰의 관계를 선행연구에서 살펴보면, Fornell et al. (1996)은 고객만족은 서비스 과정에 대한 고객참여를 강화하며 시간
의 흐름에 따라 서비스업체에 대한 신뢰와 애착심으로까지 영향을 미친다고 하였으며, Cha (2000)는 서비스가 본질적으로 신뢰를 전 제하지는 않지만 서비스를 평가함으로써 고객만족이 향상됨에 따라 신뢰의 수준이 증가하고, 불확실성과 가변성을 제거할 수 있는 특별 한 서비스를 고객에게 제공할 경우 신뢰감이 커진다고 하였다. 이와 같은 선행연구를 바탕으로 고객만족은 신뢰에 유의적인 영향을 미칠 것이라고 추론할 수 있으므로 다음과 같은 가설을 설정할 수 있다.

$\mathrm{H} 2$ : 네일 미용산업의 고객만족이 신뢰에 유의적인 영향을 미칠 것이다.

3) 네일 미용산업의 신뢰가 재방문 의도에 미치는 영향 관계

Parasuraman et al. (1985)은 신뢰가 정보제공 의지나 정보를 수 용하려는 태도에 정(+)의 영향을 미친다는 사실을 밝히고 있으며, 고객이 제품을 구매 시 고객만족이 신뢰에 영향을 주며 신뢰와 고객 만족 모두 재방문 의도에 유의한 영향을 미친다고 하였다. 이와 같은 선행연구를 바탕으로 신뢰가 재방문 의도에 유의적인 영향을 미칠 것이라고 추론할 수 있으므로 다음과 같은 가설을 설정할 수 있다.

H3: 네일 미용산업의 신뢰가 재방문 의도에 유의적인 영향을 미 칠 것이다.

Table 1. Demographic characteristics of the sample

\begin{tabular}{|c|c|c|c|}
\hline Variables & & Frequency $(\mathrm{N})$ & Percent (\%) \\
\hline \multirow{2}{*}{ Gender } & Male & 11 & 4.6 \\
\hline & Female & 227 & 95.4 \\
\hline \multirow{4}{*}{ Age } & Under 30 & 96 & 40.3 \\
\hline & $30-40$ & 128 & 53.8 \\
\hline & $40-50$ & 9 & 3.8 \\
\hline & Over 50 & 5 & 2.1 \\
\hline \multirow{2}{*}{ Marital status } & Married & 136 & 57.1 \\
\hline & Single & 102 & 42.9 \\
\hline \multirow{5}{*}{ Income } & $\mathrm{KRW}<2,000,000$ & 36 & 15.1 \\
\hline & KRW 2,000,000-3,000,000 & 62 & 26.1 \\
\hline & KRW 3,000,000-4,000,000 & 86 & 36.1 \\
\hline & KRW 4,000,000-5,000,000 & 33 & 13.9 \\
\hline & $\mathrm{KRW}>5,000,000$ & 21 & 8.8 \\
\hline \multirow{6}{*}{ Job } & Office & 93 & 39.1 \\
\hline & Sales/service & 42 & 17.6 \\
\hline & Professional & 29 & 12.2 \\
\hline & Government employee & 38 & 16.0 \\
\hline & House-wife & 30 & 12.6 \\
\hline & Others & 6 & 2.5 \\
\hline Total & & 238 & 100.0 \\
\hline
\end{tabular}




\section{4. 자료수집 및 분석방법}

\section{1) 조사대상}

본 연구는 네일 미용산업의 서비스 품질이 고객만족, 신뢰 및 재 방문 의도에 미치는 영향에 대한 연구로 서울·경기 지역의 네일 미용산업을 대상으로 조사하였다. 서울 - 경기 소재 네일 미용산업 을 방문한 경험이 있는 고객을 대상으로 2016년 6월 13일부터 6월 30 일까지 총 252 부의 설문지를 배포하여 자기 기입 설문지를 작성 하도록 의뢰하였으며, 회수된 설문지 중 불성실한 설문지 14 부를 제외하고 총 238 부를 본 연구의 분석에 사용하였다.
2) 자료분석방법

수집된 자료는 데이터 코딩 과정을 거쳐 SPSS (ver. 21; IBM, USA)를 이용하여 빈도분석 및 상관관계분석과 탐색적 요인분석 을 통하여 신뢰도와 타당도를 검증하였다. 본 연구는 연구모형에 서 제시된 구성개념들 간에 상호 관계를 검증하고 평가하는데 유 용한 analysis of moment structure (AMOS, SPSS AMOS 21; $\mathrm{IBM})$ 를 이용하였다. 구조방정식 모형은 공분산 구조방정식이라 고도 불리는데, 이는 확인적 요인분석을 통해서 측정 오차가 없 는 잠재요인을 발견하고 회귀분석으로 잠재요인 간을 연결하는 방법으로 요인분석과 회귀분석을 결합한 형태라고 할 수 있다.

Table 2. Reliability analysis

\begin{tabular}{|c|c|c|}
\hline Classification & & Cronbach's $\alpha$ \\
\hline \multirow{9}{*}{ Service quality } & Appropriateness of quality versus price ratio for nail services & 0.892 \\
\hline & Nail technology for price adequacy & 0.881 \\
\hline & Style as desired procedure & 0.891 \\
\hline & Exactly the procedure at the appointed time & 0.869 \\
\hline & Nail treatments-the simplicity of the procedure & 0.812 \\
\hline & Convenience of booking & 0.879 \\
\hline & Kindness of the contact employees & 0.921 \\
\hline & Kindness of contact in the event of a problem employees & 0.911 \\
\hline & Kindness of a reservation for employees & 0.895 \\
\hline \multirow{4}{*}{ Customer satisfaction } & Service satisfaction of the relationship & 0.892 \\
\hline & Service levels are appropriate & 0.869 \\
\hline & Enjoyment of the relationship & 0.876 \\
\hline & Usefulness of services & 0.781 \\
\hline \multirow{4}{*}{ Trust } & Services that meet the customer's expectations & 0.841 \\
\hline & Using high-quality products & 0.874 \\
\hline & The same quality of service & 0.862 \\
\hline & Trust in services & 0.881 \\
\hline \multirow{4}{*}{ Revisit intention } & Shop if they consider to be rational use & 0.896 \\
\hline & Recommend to someone else & 0.938 \\
\hline & Intention to visit again & 0.805 \\
\hline & High frequency visit & 0.891 \\
\hline
\end{tabular}

Table 3. Validity analysis

\begin{tabular}{lcccc}
\hline Classification & GFI & AGFI & RMR & $x^{2}$ \\
Service quality & 0.918 & 0.912 & 0.049 & 3.436 \\
Customer satisfaction & 0.932 & 0.896 & 0.035 & 3.638 \\
Trust & 0.936 & 0.917 & 0.042 & 3.246 \\
Revisit intention & 0.927 & 0.909 & 0.050 & 3.158 \\
\hline
\end{tabular}

GFI, goodness of fit index; AGFI, adjusted goodness of fit index; RMR, root mean square residual; $x^{2}$, chi-squared test. 


\section{Results and Discussion}

\section{1. 표본의 인구 통계적 특성}

본 연구 설문에 응답한 표본의 인구 통계적 특성은 Table 1과 같 다. 성별은 남자가 11 명(4.6\%), 여자가 227 명(95.4\%)로 나타났으며, 연령별 분포는 30-40세가 128 명(53.8\%)으로 가장 높게 나타났고 50 세 이상의 경우 5 명(2.1\%)로 가장 낮게 나타났다. 결혼여부는 기혼 이 136명(57.1\%)로 높게 나타났으며, 소득은 300-400만원이 86명 (36.1\%)로 가장 높게 나타났고 500만원 이상이 21명(8.8\%)로 가장 낮게 나타났다. 직업은 회사원이 93명(39.1\%)로 가장 높게 나타났으 며 영업 42명(17.6\%), 공무원 38명(16.0\%), 주부 30명(12.6\%), 전문 직 29 명(12.2\%), 기타 6 명(2.5\%)의 분포를 보였다.

\section{2. 측정도구의 신뢰도와 타당도 분석}

1) 신뢰도 분석

신뢰도(reliability)란 동일한 개념에 대해 측정을 반복했을 때 동 일한 측정값을 얻을 가능성을 말하는 것으로 측정된 결과치의 안정 성, 일관성, 예측가능성, 정확성 등과 관련된 개념이다. 본 연구에서 는 신뢰도 개념 중에서 널리 인정하고 있는 Cronbach's $\alpha$ 값을 구하 는 방법을 시행하였다. 일반적인 사회과학 연구에서 탐색적인 연구 단계에서는 Cronbach's $\alpha$ 값이 0.60 이상이면 신뢰도가 높다고 보고 있다(Chaiy, 2001).

본 연구에서는 다항목(multi-items)으로 측정하였다. 서비스 품 질에 대한 신뢰도 분석결과 Cronbach's $\alpha$ 값이 최소 0.812 에서 최대 0.921 로 나타나 측정변수들은 전반적으로 높은 내적 일관성을 가지 고 있는 것으로 평가될 수 있으며 척도들의 신뢰도는 모두 유의하다 고 할 수 있다. 그리고 고객만족에 대한 신뢰도 분석결과 Cronbach' $\mathrm{s} \alpha$ 값이 최소 0.781 에서 최대 0.892 로 나타나 측정변수들은 전반적 으로 높은 내적 일관성을 가지고 있는 것으로 나타났다. 또한 신뢰는 Cronbach's $\alpha$ 값이 0.841 이상으로 나타나 측정변수들은 전반적으로 높은 내적 일관성을 가지고 있는 것으로 나타났으며, 재방문 의도는 Cronbach's $\alpha$ 값이 최소 0.805 에서 최대 0.938로 나타나 측정변수들 은 전반적으로 높은 내적 일관성을 가지고 있는 것으로 평가될 수 있 으며 척도들의 신뢰도는 모두 유의하다고 할 수 있다(Table 2).
2) 타당도 분석

변수의 타당도를 확인하기 위하여 확인적 요인분석을 실시하였다. 확인적 요인분석은 이론적 배경을 바탕으로 변수들을 검증하는 방 법으로 측정모델들의 적합도를 평가하는 방법 중에는 $\chi^{2}$ 검증을 하 는 것과 적합도 지수를 사용하는 방법이 있는데, $\chi^{2}$ 값은 표본의 크 기에 민감하고 영가설이 쉽게 기각될 가능성이 높으므로 적합도를 평가할 때 $\chi^{2}$ 검증만 의존하지 않고 다른 적합도 지수들을 함께 판단 해야 한다. 확인적 요인분석 결과를 살펴보면, goodness of fit index (GFI) 0.9 이상, adjusted goodness of fit index (AGFI) 0.85 이상, root mean square residual (RMR) 0.08 이하에서 적합하다고 판단 하므로 전반적으로 모형이 수용 가능한 것으로 나타났다(Table 3).

\section{3. 가설 검증과 해설}

1) 모형의 적합성 검증

전체적인 모형의 적합도를 평가하기 위한 $\chi^{2}$ 통계량, degrees of freedom (df), RMR, GFI, AGFI, normed fit index (NFI)의 기준을 이용한 결과 전체 모형의 경우 $\chi^{2}=159.28, \mathrm{GFI}=0.958, \mathrm{AGFI}=0.943$, $\mathrm{NFI}=0.921$ (0.9 이상 1.0 미만이 되어야 적합)의 지수로 나타나 모형 에 있어서 적합하다고 할 수 있다(Table 4).

\section{2) 가설 검증}

Table 5에 나타난 바와 같이 서비스 품질인 경제성이 고객만족에 미치는 영향을 살펴보면 경로계수( $\mathrm{E}=0.212 ; \mathrm{t}$-value=2.627)로 유 의한 영향을 미침을 알 수 있다. 따라서 가설 1-1, "네일 미용산업의 서비스 품질인 경제성은 고객만족에 유의적인 영향을 미칠 것이다." 의 가설이 채택되었다.

서비스 품질인 확신성이 고객만족에 미치는 영향을 살펴보면 경 로계수 $(\mathrm{E}=0.386 ; \mathrm{t}-\mathrm{value}=4.781)$ 로 유의한 영향을 미침을 알 수 있 다. 따라서 가설 1-2, "네일 미용산업의 서비스 품질인 확신성은 고 객만족에 유의적인 영향을 미칠 것이다."의 가설이 채택되었다.

서비스 품질인 공감성이 고객만족에 미치는 영향을 살펴보면 경 로계수( $\mathrm{E}=0.113 ; \mathrm{t}$-value=2.024)로 유의적인 영향을 미침을 알 수 있다. 따라서 가설 1-3, "네일 미용산업의 서비스 품질인 공감성은 고객만족에 유의적인 영향을 미칠 것이다."의 가설이 채택되었다.

Table 4. Analysis of the goodness of fit of the research model

\begin{tabular}{lccccccc}
\hline \multirow{2}{*}{ Factor } & \multicolumn{5}{c}{ Goodness of fit index } \\
\cline { 2 - 7 } & $x^{2}$ & df & RMR & GFI & AGFI & NFI \\
Structural model & 159.28 & 169 & 0.021 & 0.958 & 0.943 & 0.921 \\
\hline
\end{tabular}

$\mathrm{X}^{2}$, chi-squared test; df, degrees of freedom; RMR, root mean square residual; GFI, goodness of fit index; AGFI, adjusted goodness of fit index; NFI, normed fit index. 
서비스 품질인 친절성이 고객만족에 미치는 영향을 살펴보면 경 로계수 $(\mathrm{E}=0.284 ; \mathrm{t}$-value=3.623)로 유의한 영향을 미침을 알 수 있 다. 따라서 가설 1-4, "네일 미용산업의 서비스 품질인 친절성은 고 객만족에 유의적인 영향을 미칠 것이다.”의 가설이 채택되었다.

고객만족이 신뢰에 미치는 영향을 살펴보면 경로계수 $(\mathrm{E}=0.227$; $\mathrm{t}$-value=2.729)로 유의한 영향을 미침을 알 수 있다. 따라서 가설 2 , "네일 미용산업의 고객만족이 신뢰에 영향을 미칠 것이다."의 가 설이 채택되었다.

신뢰가 재방문 의도에 미치는 영향을 살펴보면 경로계수 $(\mathrm{E}=0.268 ; \mathrm{t}-\mathrm{value}=3.784)$ 로 유의한 영향을 미침을 알 수 있다. 따 라서 가설 3, "네일 미용산업의 신뢰가 재방문 의도에 영향을 미칠 것이다."의 가설이 채택되었다.

결론적으로 네일 미용산업의 경우에는 서비스가 가지는 특성상 기술적인 부분만이 아닌 전반적인 서비스 품질이 고객만족, 신뢰 및 재방문 의도에 영향을 미침으로써 점포에 대한 몰입과 충성하게 하 는 원인이라는 것을 알 수 있다.

\section{Conclusion}

본 연구는 네일 미용산업의 서비스 품질이 고객만족, 신뢰 및 재 방문 의도에 미치는 영향에 관한 연구로서, 서비스 품질이 고객만 족, 신뢰 및 재방문 의도에 미치는 영향 요인을 도출하고자 하였다. 또한 서비스 품질을 경제성, 확신성, 공감성, 친절성 요인으로 구분 하여 고객만족, 신뢰, 재방문 의도와의 영향을 규명하고자 하였다.

본 연구의 결과를 요약하면 다음과 같다.

첫째, 서비스 품질인 경제성이 고객만족에 미치는 영향 $(\mathrm{E}=0.212$; $\mathrm{t}$-value=2.627)은 통계적으로 매우 유의한 긍정적인 영향을 미치는 것으로 나타났으며, 이는 네일 서비스 품질 대비 가격 적정성, 네일 기술 대비 가격 적정성 요인이 고객만족에 영향을 미친다는 것을 의 미한다.

둘째, 서비스 품질인 확신성이 고객만족에 미치는 영향 $(\mathrm{E}=0.386$; $\mathrm{t}-\mathrm{value}=4.781)$ 은 통계적으로 매우 유의한 긍정적인 영향을 미치는 것으로 나타났으며, 이는 원하는 스타일을 정확히 시술, 약속시간에
정확히 시술하는 요인이 고객만족에 영향을 미친다는 것을 의미한 다.

셋째, 서비스 품질인 공감성이 고객만족에 미치는 영향 $(\mathrm{E}=0.113$; $\mathrm{t}$-value=2.024)은 통계적으로 유의한 것으로 나타났으며, 이는 네 일 시술 절차의 간편성, 예약 신청의 편리성 요인이 고객만족에 영 향을 미친다는 것을 의미한다.

넷째, 서비스 품질인 친절성이 고객만족에 미치는 영향 $(\mathrm{E}=0.284$; t-value=3.623)은 통계적으로 매우 유의한 긍정적인 영향을 미치는 것으로 나타났으며, 이는 접점 종업원의 친절도, 문제 발생시 접점 종업원의 친절도, 예약 직원의 친절도 요인이 고객만족에 영향을 미 친다는 것을 의미한다.

가설 2 의 검증 결과, 고객만족이 신뢰에 미치는 영향 $(\mathrm{E}=0.227$; $\mathrm{t}$-value $=2.729)$ 은 통계적으로 매우 유의한 긍정적인 영향을 미치 는 것으로 나타났다. 이는 네일 미용서비스 관계의 만족감, 네일 미 용서비스 수준의 적절함, 관계의 즐거움, 서비스의 유익함이 신뢰에 영향을 미친다는 것을 알 수 있다.

가설 3 의 검증 결과, 신뢰가 재방문 의도에 미치는 영향 $(\mathrm{E}=0.268 ; \mathrm{t}-\mathrm{value}=3.784)$ 은 통계적으로 매우 유의한 긍정적인 영 향을 미치는 것으로 나타났다. 이는 기대에 부응하는 네일 미용산업 서비스, 고품질 제품의 사용, 동일한 서비스 품질, 네일 미용산업 서비 스의 신뢰도 요인이 재방문 의도에 영향을 미친다는 것을 알 수 있다.

본 연구결과가 가지는 마케팅적 시사점은 네일 미용산업에 가장 큰 영향을 미치는 서비스 품질 요인은 경제성, 확신성, 공감성, 친절 성이다. 서비스 품질 요인이 네일 미용산업의 고객만족, 신뢰 및 재 방문 의도에 영향을 미치므로 이를 맞추고자 하는 노력이 필요하다. 이는 네일 미용산업에서 고객이 인식하는 경제성, 확신성, 공감성, 친절성이 향후 고객만족과 신뢰, 재방문 의도에 영향을 많이 주는 요인임으로 이러한 노력을 기울이면서 고객에게 신뢰감을 주고 고 객지향성을 높이는 섬세한 지속적인 관리와 장기적인 관계가 구축 될 때 재방문 의도가 높아짐으로써 자연스럽게 고객이탈을 방지할 수 있을 것이다.

본 연구의 한계점으로는 서비스 품질에 영향을 미치는 여러 가지 변수를 보다 폭넓게 연구대상으로 포함시키지 못하고 선택된 변수 만으로 탐색적 연구로 한정하여 이것이 네일 미용산업의 서비스 품

Table 5. Results of experimental analysis of the research model and hypotheses

\begin{tabular}{llccccc}
\hline Hypotheses & Path & E & S.D. & t-value & $p$-value & Results \\
H1-1 & Economy $\rightarrow$ Customer satisfaction & 0.212 & 0.079 & $2.627^{* * *}$ & 0.000 & Accepted \\
H1-2 & Conviction $\rightarrow$ Customer satisfaction & 0.386 & 0.081 & $4.781^{* * *}$ & 0.000 & Accepted \\
H1-3 & Sympathy $\rightarrow$ Customer satisfaction & 0.113 & 0.056 & $2.024^{* * *}$ & 0.045 & Accepted \\
H1-4 & Kindness $\rightarrow$ Customer satisfaction & 0.284 & 0.079 & $3.623^{* * *}$ & 0.000 & Accepted \\
H2 & Customer satisfaction $\rightarrow$ Trust & 0.227 & 0.083 & $2.729^{* * *}$ & 0.000 & Accepted \\
H3 & Trust $\rightarrow$ Revisit intention & 0.268 & 0.071 & $3.784^{* * *}$ & 0.000 & Accepted \\
\hline
\end{tabular}

E, path coefficient; S.D., standard deviation; ${ }^{* * *} p<0.05$. 
질 결정요인을 대표한다고 할 수 없다는 한계점을 가지고 있다. 따 라서 향후 연구에서는 네일 미용산업의 서비스 품질에 영향을 미치 는 다양한 환경적 변수를 분석할 필요성이 있다.

\section{References}

Anderson EW, Fornell C, Lehmann DR. Customer satisfaction, market share, and profitability: findings from Sweden. Journal of Marketing, 58: 53-66, 1994.

Cha BK. A study on the factors and model of hotel relationship marketing. Journal of Industrial Economics and Business, 13: 259-291, 2000.

Chaiy S. Social science research methodology (2nd edition). Hakhyunsa, Paju, pp235-269, 2001.

Cho JE, Choi SS. The effects of human service quality of airlines on word of mouth and repurchase intention. Journal of Hospitality and Tourism Studies, 41: 222-235, 2011.

Cronin JJ Jr, Taylor SA. Measuring service quality: a reexa mination and extension. Journal of Marketing, 56: 55-68, 1992.

Fornell C, Johnson MD, Anderson EW, Cha J, Bryant BE. The American customer satisfaction index: nature, purpose, and findings. Journal of Marketing, 60: 7-18, 1996.

Houston FS. The marketing concept: what it is and what it is not. Journal of Marketing, 50: 81-87, 1986.

Kim JW, Lee SG, Choi JH. Measuring parcel service quality. Korean Management Review, 31: 283-294, 2002.

Lee $\mathrm{MH}$. The study on the effect of airline service quality on value, satisfaction and loyalty. International Journal of Tourism Management and Science, 25: 101-122, 2010.

Morgan RM, Hunt SD. The commitment-trust theory of relationship marketing. Journal of Marketing, 58: 20-38, 1994.

Oliver RL. A cognitive model of the antecedents and consequences of satisfaction decisions. Journal of Marketing Research, 17: 460-469, 1980.

Oliver RL. Satisfaction: a behavioral perspective on the consumer. McGraw-Hill Education, New York, pp35-68, 1997.

Parasuraman A, Zeithaml VA, Berry LL. A conceptual model of service quality and its implications for future research. Journal of Marketing, 49: 41-50, 1985.

Rho EK, Oh SH. The relationships between patient's perceived quality of healthcare service and intention to re-visit. Journal of Korean Academy of Nursing Administration, 14: 176-181, 2008. 


\section{국문초록}

\section{네일 미용산업의 서비스 품질이 고객만족, 신뢰 및 재방문 의도에 미치는 영향}

박선주

용인대학교 뷰티헬스케어학과, 경기도 용인시, 한국

목적: 본 연구는 네일 미용산업의 서비스 품질이 재방문 의도에 미치는 영향에 관해 알아보고자 진행되었다. 방법: 네일 미용산 업에서 서비스 품질에 따른 고객의 반응이 고객만족, 신뢰, 재방문 의도에 어떠한 영향을 미치는지를 규명하기 위해 Statistical Package for the Social Sciences (SPSS) 분석을 실시하였다. 결과: 본 연구결과가 가지는 마케팅적 시사점은 네일 서비스산업에 가 장 큰 영향을 미치는 서비스 품질 요인은 경제성, 확신성, 공감성, 친절성이다. 결론: 서비스 품질 요인이 네일 샵의 고객만족, 신뢰 및 재방문 의도에 영향을 미치므로 이를 맞추고자 하는 노력이 필요하다. 이는 네일 미용산업에서 고객이 인식하는 경제성, 확신성, 공감성, 친절성이 향후 고객만족과 신뢰, 재방문 의도에 영향을 많이 주는 요인임으로 이러한 노력으로 고객지향성을 높이고 고객 에게 신뢰감을 주어 장기적인 관계가 구축될 때 재방문 의도가 높아짐으로써 자연스럽게 고객이탈을 방지할 수 있을 것이다.

핵심어: 서비스 품질, 고객만족, 신뢰, 재방문 의도, 네일 미용산업

\section{참고문헌}

김재욱, 이성근, 최지호. 택배서비스 품질의 측정에 관한 연구. 경영학연구, 31: 283-294, 2002.

노은경, 오숙희. 대상자가 인지한 의료서비스 질과 재이용 의도와의 관계. 간호행정학회지, 14: 176-181, 2008.

이미혜. 항공사 서비스품질이 가치, 만족 및 충성도에 미치는 영향. 관광연구, 25: 101-122, 2010.

조주은, 최상수. 항공사 인적서비스 품질이 구전과 재구매 의도에 미치는 영향에 관한 연구. 호텔관광연구, 41: 222-235, 2011.

차부근. 호텔관계마케팅의 영향요인과 요인간의 관계모델 구축에 관한 연구. 산업경제연구, 13: 259-291, 2000.

채서일. 사회과학 조사방법론 (2판). 학현사, 파주, pp235-269, 2001. 


\section{中文摘要}

\section{指甲美容行业服务质量对顾客满意、信任和再访意愿的影响}

朴善柱

龙仁大学美容保健科，京畿道龙仁市，韩国

目的: 探讨指甲美容业服务品质对顾客再访意愿的影响。方法: 探讨顾客对服务品质的反应如何影响指甲美容业的顾客满 意、信任及再访意愿。为此，采用Statistical Package for the Social Sciences（SPSS）进行数据分析。结果：从营销学的 角度来看，指甲美容行业的服务质量最重要的影响因素是经济、信念、共感和亲切。结论: 服务品质因数对美甲行业的 顾客满意度, 信任度及再访意愿产生影响, 因此, 应努力应对。在美甲行业中, 顾客认可的经济、信念、共感和亲切是 影响未来顾客满意、信任和再访意愿的主要因素。基于这些因素, 美甲行业应努力满足客户需求, 以客户为中心, 值得 信赖。通过与客户建立长期的关系，美甲行业将获得高客户回访意向，从而防止客户流失。

关键词: 服务品质，顾客满意，信任，再访意愿，指甲美容业 
